\title{
MODIFIED POLYMERS FROM CIS-1,4-POLYISOPRENE
}

\section{Introduction}

Chemical transformation of functional groups in polymers has often been used as a method to prepare polymers with specific properties (1). Polymer-analogous reactions with polydienes have been described $(2,3)$ and recently we reported on the chemical modification of polyisoprenes $(4,5)$. By addition of chlorosulfonyl isocyanate ( $\mathrm{CSI}$ ) to $\mathrm{C}=\mathrm{C}$ bonds, modified polyisoprenes were obtained with $\mathrm{N}$-chlorosulfonyl $\beta$-lactam and $\beta, \gamma$-unsaturated $\mathrm{N}$-chlorosulfonyl carbonamide groups. A second-step modification by reaction with $\mathrm{NaOH}$ resulted in the formation of water-soluble polyelectrolytes with anticoagulant activity (5-7).

This article deals with the modification of cis-1,4-polyisoprene and results are presented which give information about the chemical structure of the modified polymers.

\section{Experimental}

Solutions of cis-1,4-polyisoprene (Cariflex IR 307, cis content more than $96 \%$ ) in toluene $(0.2 \mathrm{M})$ were added to stirred solutions of CSI in the same solvent. Reactions were carried out at 0 or $20^{\circ} \mathrm{C}$ in a nitrogen atmosphere. After $1 \mathrm{hr}$ the solid cis-1,4-polyisoprene-CSI adducts were isolated and washed with diethylether. Polyelectrolytes were synthesized from these adducts by heating with $2 \mathrm{M} \mathrm{NaOH}$ for $1 \mathrm{hr}$. Subsequently they were precipitated by pouring the alkaline solutions in ethanol.

More experimental details have been published elsewhere $(4,5)$.

\section{Results and Discussion}

The reaction of cis-1,4-polyisoprene with CSI (Scheme I) leads to the formation of a modified polymer with predominantly structure a, whereas structure $\mathrm{b}$ is also formed $(4,5)$. It was found that with a $50 \%$ molar excess of CSI, addition takes place to an extent of $65 \%$ at $20^{\circ} \mathrm{C}$ (Table I, exp. 1). The degree of addition decreases by lowering the temperature, as can be seen from the results of exp. 2. The effect of a prolonged reaction time $(6 \mathrm{hr})$ is supposed to be of minor importance, because an increase of the reaction time (exp. 3) does not lead to an increase of the degree of addition (cf. also the results of exps. 5 and 6). The effect of an increase of the CSI :cis-1,4-polyisoprene molar ratio, on the other hand, is apparent, as can be seen from the results of exps. 3 and 4.

The degree of addition in exps. 4, 5, and 6 is about the same. Evidently the use of a large excess of CSI is not necessary and is even unfavorable, as can be seen from the data in Table II. 

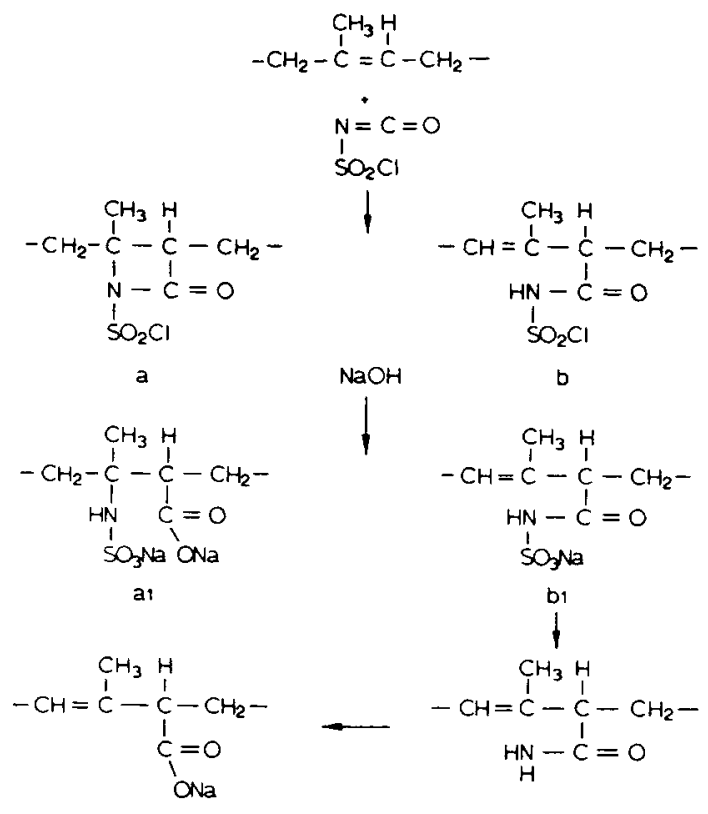

b3

b2

Scheme I. Structural units in modified cis-1,4-polyisoprene.

\section{TABLE I}

Addition Products from Cis-1,4-Polyisoprene with CSI

\begin{tabular}{|c|c|c|c|c|c|c|}
\hline Exp. & $1^{a}$ & 2 & 3 & 4 & 5 & 6 \\
\hline $\begin{array}{l}\text { Molar } \\
\text { ratio } \\
\text { CSI : PI }\end{array}$ & 1.5 & 1.5 & 1.5 & 3.0 & 30.0 & 30.0 \\
\hline $\begin{array}{l}\text { Reaction } \\
\text { time (hrs) }\end{array}$ & 1.5 & 6.0 & 22 & 22 & 22 & 1.5 \\
\hline Temp. ${ }^{0} \mathrm{C}$. & 20 & 0 & 0 & 0 & 0 & 0 \\
\hline$c$ & 42.08 & 43.90 & 42.70 & 40.24 & 37.11 & 37.37 \\
\hline $\mathrm{H}$ & 5.07 & 5.59 & 5.00 & 4.92 & 4.82 & 4.58 \\
\hline $\mathrm{N}$ & 5.66 & 5.43 & 5.40 & 5.96 & 6.03 & 6.01 \\
\hline 0 & 19.47 & 19.41 & 18.89 & 20.31 & 23.59 & 22.05 \\
\hline$S$ & 12.88 & 12.64 & 12.14 & 13.63 & 13.38 & 14.33 \\
\hline $\mathrm{Cl}$ & 13.97 & 13.76 & 13.66 & 15.16 & 15.16 & 15.53 \\
\hline $\begin{array}{l}\text { Additioz } \\
(\operatorname{mol} \delta)\end{array}$ & 65 & 58 & 58 & 73 & 75 & 74 \\
\hline
\end{tabular}

${ }^{\mathrm{a}}$ Reference 5 .

${ }^{\mathrm{b}}$ Calculated on $\% \mathrm{~N}$. 
TABLE II

Atomic Ratios in Cis-1,4-Polyisoprene-CSI Adducts

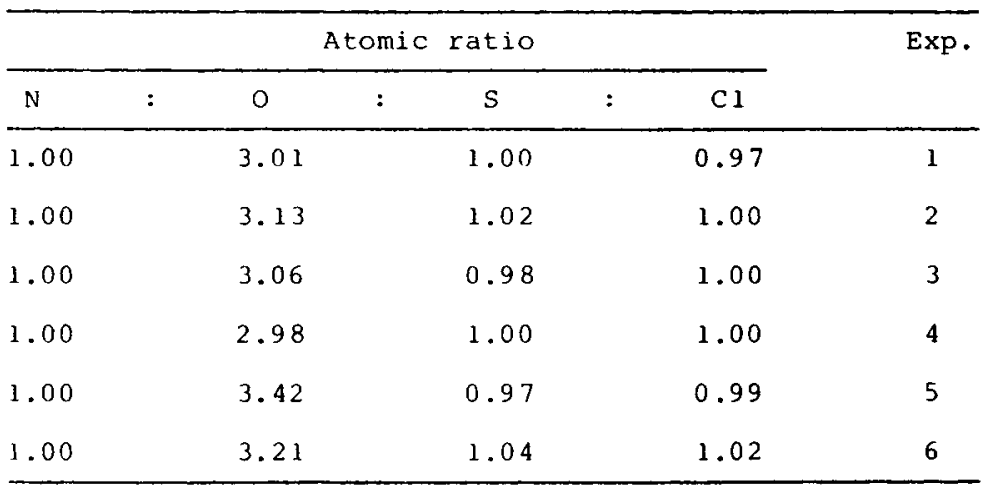

Table II shows some of the atomic ratios in the modified polymers. The $\mathrm{N}: \mathrm{S}: \mathrm{Cl}$ ratios are not very different from the theoretical ones. However, the $\mathrm{N}: \mathrm{O}$ ratios in the products, obtained from exps. 5 and 6 , are lower than expected, probably resulting from secondary reactions. The promotion of such reactions, due to the use of an excess of reagent, has also been reported for other polymer-analogous conversions (8).

From the CSI adducts, water-soluble polyelectrolytes were obtained by reaction with $\mathrm{NaOH}(4,5)$. It was assumed that in structure a (see (Scheme I) only rupture between $\mathrm{N}$ and $\mathrm{C}=\mathrm{O}$ bonds had occurred (9), leading to structure al. Likewise structure $\mathrm{b}$ was supposed to give structure $\mathrm{bl}$, whereas cleavage of bonds between $\mathrm{N}$ and $\mathrm{S}$ or $\mathrm{N}$ and $\mathrm{C}=\mathrm{O}$ could lead to structure $\mathrm{b} 2$ or $\mathrm{b} 3$, respectively $(10,11)$.

In Table III the $\mathrm{C}: \mathrm{N}, \mathrm{C}: \mathrm{S}$, and $\mathrm{N}: \mathrm{S}$ ratios are given for two cis-1,4-polyisoprene-CSI adducts $(A, B)$ and for the polyelectrolytes derived from them $\left(A^{\prime}\right.$, $\left.B^{\prime}\right)$. From Scheme $I$ it is evident that hydrolysis of structure $b$ to structure b2 should result in an increase in the $\mathrm{C}: \mathrm{S}$ ratio as compared with the value in the cis-1,4-polyisoprene-CSI adduct, whereas the $\mathrm{C}: \mathrm{N}$ ratio should not change. The hydrolysis of structure b to structure b3, as previously supposed (4), should result in an increase of both the $\mathrm{C}: \mathrm{S}$ and $\mathrm{C}: \mathrm{N}$ ratios.

The data in Table III show that the $\mathrm{C}: \mathrm{S}$ ratios have hardly changed, going from $A$ to $A^{\prime}$ and from $B$ to $B^{\prime}$, respectively. The same is true for the $C: N$ ratios, and therefore the formation of structure $b 2$ or $b 3$ from structure $b$ cannot be concluded from these results.

More information about the structure of the polyelectrolytes was necessary, however, in order to elucidate the relationship between the structure and the anticoagulant activity of the polyelectrolytes. It has been reported that these polyelectrolytes show anticoagulant activity (5-7), and there are reasons to assume that the presence of structure al in the polyelectrolytes is essential for the activity. Cleavage of $\mathrm{N}-\mathrm{S}$ bonds in structure al results in a decrease of 
TABLE III

Conversion of Cis-1,4-Polyisoprene-CSI Adducts with $\mathrm{NaOH}$

\begin{tabular}{|c|c|c|c|c|c|}
\hline \multirow[t]{2}{*}{$\begin{array}{l}\text { Atomic } \\
\text { ratio }\end{array}$} & \multicolumn{2}{|c|}{$\begin{array}{l}\text { cis-1,4-Polyiso- } \\
\text { prene-CSI adduct }\end{array}$} & \multicolumn{2}{|c|}{$\begin{array}{l}\text { Polyelectrolyte from } \\
\text { reaction with } \mathrm{NaOH}\end{array}$} & \multirow[t]{2}{*}{ Ref. } \\
\hline & A & B & $A^{\prime}$ & $\mathrm{B}^{\prime}$ & \\
\hline$c: N$ & 7.85 & 8.70 & 8.13 & 8.88 & $\begin{array}{l}(4) \\
(5)\end{array}$ \\
\hline$c: s$ & 8.21 & 8.70 & 8.14 & 8.77 & $\begin{array}{l}(4) \\
(5)\end{array}$ \\
\hline$N: S$ & 1.05 & 1.00 & 1.00 & 0.99 & $\begin{array}{l}(4) \\
(5)\end{array}$ \\
\hline
\end{tabular}

the anticoagulant activity and an increase in the $\mathrm{N}: \mathrm{S}$ ratio (5). We have found that dialysis of the polyelectrolytes increased the anticoagulant activity. In addition, the atomic ratios in the dialyzed products gave information about the structure of the polyelectrolytes.

In Table IV atomic ratios are given for two polyelectrolytes, before and after dialysis. The polyelectrolytes $C^{\prime}$ and $D^{\prime}$ have been synthesized in the same way as $A^{\prime}$ and $B^{\prime}$ and the $C: N$ and $C: S$ ratios before dialysis are not significantly different from the values in $\mathbf{A}^{\prime}$ and $\mathbf{B}^{\prime}$, respectively. From Table IV it can be seen that in the dialyzed polyelectrolytes $C^{\prime \prime}$ and $D^{\prime \prime}$ somewhat smaller $\mathrm{C}: \mathrm{N}$ ratios were found, whereas larger $\mathrm{C}: \mathrm{S}$ and $\mathrm{N}: \mathrm{S}$ ratios were observed. The increase in the $C: S$ ratios means loss of sulfur, but it is unlikely that cleavage of $\mathrm{N}-\mathrm{S}$ bonds has occurred under the dialysis conditions.

Assuming that no isomerization of structure a into structure b occurs, conversion of structure a in the presence of $\mathrm{NaOH}$ will lead to structure al and also to release of $\mathrm{NaCl}$ (Scheme I). In the formation of structure b2 from structure $b$, however, not only $\mathrm{NaCl}$ but also $\mathrm{Na}_{2} \mathrm{SO}_{4}$ will be released. It seems, therefore, quite reasonable that part of the inorganic compounds $(\mathrm{NaCl})$ remained in solution after precipitation of the alkaline solutions with ethanol, the usual procedure for the isolation of the polyelectrolytes. The $\mathrm{Na}_{2} \mathrm{SO}_{4}$, on the other hand, precipitated together with the polyelectrolytes and yas removed by dialysis, resulting in an increase in the $\mathrm{C}: \mathrm{S}$ ratios in the dialyzed polyelectrolytes. Conversion of structure $b 2$ into structure $b 3$ should lead to a $\mathrm{Na}: \mathrm{S}$ ratio larger than 2 and a $\mathrm{N}: \mathrm{S}$ ratio of 1 . The $\mathrm{Na}: \mathrm{S}$ ratios in the dialyzed products, however, are not very different from 2 , whereas the $\mathrm{N}: \mathrm{S}$ ratios are larger than 1 .

The results indicate that in the dialyzed polyelectrolytes, apart from unreacted isoprene units, only structure al and structure b2 are present. Based on this assumption the ratio of structural units $\mathrm{a} 1$ and $\mathrm{b} 2$ can be calculated, this ratio then being equal to the ratio of units $a$ and $b$ in the cis-1,4-polyisopreneCSI adducts. 


\section{TABLE IV}

Effect of Dialysis on Atomic Ratios in Polyelectrolytes

\begin{tabular}{|c|c|c|c|c|}
\hline \multirow[t]{3}{*}{ Atomic ratio } & \multicolumn{4}{|c|}{ Polyelectrolytes } \\
\hline & \multicolumn{2}{|c|}{ Before dialysis } & \multicolumn{2}{|c|}{ After dialysis } \\
\hline & $\mathrm{C}^{\prime}$ & $D^{\prime}$ & C" & $D^{\prime \prime}$ \\
\hline$C: N$ & 7.80 & 8.31 & 7.47 & 7.98 \\
\hline$C: S$ & 8.66 & 8.50 & 10.78 & 10.81 \\
\hline$N: S$ & 1.11 & 1.02 & 1.44 & 1.35 \\
\hline $\mathrm{Na}: \mathrm{s}$ & 2.78 & 2.32 & 1.95 & 1.90 \\
\hline
\end{tabular}

In the dialyzed products the $\mathrm{N}: \mathrm{S}$ ratio $=([\mathrm{b} 2] /[\mathrm{a} 1])+1$, which means that with a $\mathrm{N}: \mathrm{S}$ ratio of 1.44 (product $\mathrm{C}^{\prime \prime}$ ) addition of CSI to cis-1,4-polyisoprene had resulted in the formation of $70 \%$ of structure a and $30 \%$ of structure b. For a N:S ratio of 1.35 (product $D^{\prime \prime}$ ) these figures were 75 and $25 \%$, respectively.

These data are representative of the results obtained with a number of cis1,4-polyisoprene-CSI adducts, in which in general 70-80\% of structure a and $20-30 \%$ of structure $b$ appeared to be present.

It is interesting to note that addition of CSI to 2-methylbutene-2 has been reported (9) to give $80 \%$ of the $\mathrm{N}$-chlorosulfonyl $\beta$-lactam (cf. structure a) and $20 \%$ of the $\beta, \gamma$-unsaturated $\mathrm{N}$-chlorosulfonyl carbonamide (cf. structure b). Because the structural unit in cis-1,4-polyisoprene can be compared with 2methylbutene-2, the results indicate that the mode of addition of CSI to the polymer seems to be governed in a similar way by the substituents on the $\mathrm{C}=\mathrm{C}$ bonds as was found for the addition of CSI to the alkene.

\section{References}

(1) E. M. Fettes, Ed., "Chemical Reactions of Polymers," Wiley-Interscience, New York, 1964.

(2) C. Pinazzi, J.C. Brosse, A. Pleurdeau, and D. Reyx, Appl. Polym. Symp., 26, 73 (1975).

(3) G. M. Buchan and G. G. Cameron, Polymer, 19, 1089 (1978).

(4) L. van der Does, J. Hofman, and T. E. C. van Utteren, J. Polym. Sci. Polym. Lett. Ed., 11, 169 (1973).

(5) L. van der Does, T. Beugeling, P. E. Froehling, and A. Bantjes, J. Polym. Sci. Polym. Symp., 66, 337 (1979). 
(6) T. Beugeling, L. van der Does, A. Bantjes, and W. L. Sederel, J. Biomed. Mater. Res., 8, 375 (1974).

(7) T. Beugeling, L. van der Does, B. V. Rejda, and A. Bantjes, in "Biocompatibility of Implant Materials," D. Williams, Ed., Sector, London, 1976, p. 187.

(8) C. Pinazzi, J.C. Soutif, and J.-C. Brosse, Bull. Soc. Chim. Fr., 5, 1652 (1973).

(9) R. Graf, Justus Liebigs Ann. Chem., 661, 111 (1963); Angew. Chem., 80, 179 (1968).

(10) C. P. Pinazzi, P. Noireaux, and D. Reyx, Makromol. Chem., 175, 2849 (1974).

(11) A. Dorlars, in "Methoden der Organischen Chemie," E. Müller, Ed., Thieme, Stuttgart, 1958, Vol. XI/2, p. 641.

L. van der Does

J. F. van Duijl

L. C. Sederel

A. Bantjes

Department of Chemical Technology

Biomaterials Section

Twente University of Technology

Enschede, The Netherlands

Received June 13, 1979

Accepted August 21, 1979 